- before the industrial revolution. But since the Hawaiian measurements began, the values have followed an upward slope that shows no sign of levelling off (see 'On the rise'). Emissions of other greenhouse gases are also increasing, pushing the total equivalent concentration of $\mathrm{CO}_{2}$ in the atmosphere to around 478 p.p.m. in April, according to Ronald Prinn, an atmospheric scientist at the Massachusetts Institute of Technology in Cambridge.

Data compiled by Le Quéré and other members of the Global Carbon Project suggest that humans contributed around 10.4 billion tonnes of carbon into the atmosphere in 2011. About half of that is taken up each year by carbon 'sinks' such as the ocean and vegetation on land; the rest remains in the atmosphere and raises the global concentration of $\mathrm{CO}_{2}$.

"The real question now is: how will the sinks behave in the future?" says Gregg Marland, an environmental scientist at Appalachian State University in Boone, North Carolina, who helps to compile the emissions data.

The sinks have grown substantially since Keeling began his measurements, when carbon emissions totalled about 2.5 billion tonnes a year. But climate models suggest that the land and ocean will not keep pace for long.

"At some point the planet can't keep doing us a favour, particularly the terrestrial biosphere," says Jim White, a biogeochemist at the University of Colorado Boulder. As the sinks slow down and more emitted $\mathrm{CO}_{2}$ stays in the atmosphere, levels will rise even faster.

Some researchers have suggested that the sinks have already started to clog up, reducing their ability to take up more $\mathrm{CO}_{2}$ (J. G. Canadell et al. Proc. Natl Acad. Sci. USA 104,

\title{
ON THE RISE
}

Measurements of atmospheric $\mathrm{CO}_{2}$ levels at Mauna Loa, Hawaii, show that the greenhouse gas has accumulated steadily, and spiked above 400 parts per million (p.p.m) several times in April.

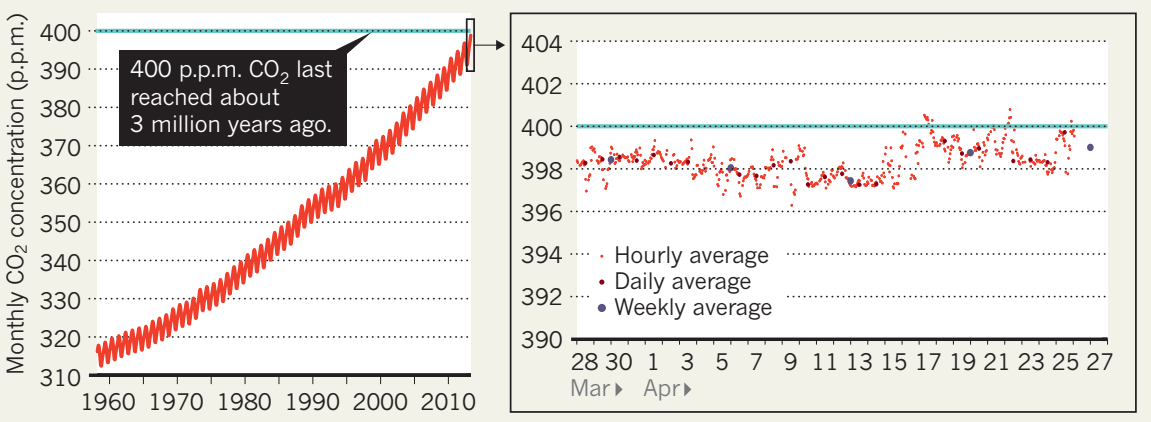

18866-18870; 2007). Others disagree.

Ashley Ballantyne, a biogeochemist at the University of Montana in Missoula, worked with White and others to examine records of emissions as well as $\mathrm{CO}_{2}$ measurements made around the globe. They found no signs of sinks slowing down (A. P. Ballantyne et al. Nature 488, $70-72 ; 2012)$. But it is difficult to be sure, says Inez Fung, a climate modeller at the University of California, Berkeley. "We don't have adequate observing networks." The largest global network, operated by the US National Oceanic and Atmospheric Administration, had to trim 12 stations in 2012 because of budget cuts.

Some of the most crucial areas, such as the tropics, are also the least monitored, although researchers are seeking to fill in the gaps. Scientists from Germany and Brazil are building a 300-metre tower to keep tabs on the Amazon (see Nature 467, 386-387; 2010). And Europe's Integrated Carbon Observation System is setting up stations throughout the continent and at some marine sites to measure $\mathrm{CO}_{2}$ and other greenhouse gases.

Satellites, too, could monitor carbon sources and sinks. Two orbiters are already providing some data, and NASA plans to launch the much anticipated Orbiting Carbon Observatory-2 next year (see page 5). An earlier version of that satellite failed during its 2009 launch.

Even as new resources come online, however, researchers are struggling to keep the Mauna Loa station going. "The amount of money that I'm able to obtain for the programme has diminished over time," says Keeling, whose group monitors $\mathrm{CO}_{2}$ concentration at 13 sites around the world.

"It's kind of silly that we chose to go all ostrich-like," says White of the funding difficulties. "We don't want to know how much $\mathrm{CO}_{2}$ is in the atmosphere, when we ought to be monitoring even more." -

\section{Flu papers spark row over credit for data}

\section{Rush to publish on H7N9 avian flu upsets Chinese scientists.}

\section{BY DECLAN BUTLER AND DAVID CYRANOSKI}

$\mathrm{O}$ n 31 March, China reported the first human cases of infection with a new H7N9 avian flu virus. The same day, a team at the Chinese National Influenza Center (CNIC) in Beijing uploaded to a research database the genetic sequences of viruses isolated from the first three human cases. But Nature has learned that in the days that followed, Chinese scientists and officials grew increasingly concerned that China might lose credit for its work in isolating and sequencing the virus.
The sequences were placed in the Global Initiative on Sharing All Influenza Data (GISAID) database. According to the database's rules, scientists who use sequences from it must credit those who deposited the data and, where possible, propose collaborations with them.

"Unfortunately some bad things happened when we released the sequences in GISAID, and they really hurt us," says Yuelong Shu, head of the CNIC, which is also the World Health Organization (WHO) Collaborating Centre for Reference and Research on Influenza in China. "GISAID have tried their best to help us," he adds. "I really appreciate what they have done."

Shu did not initially reveal specific concerns, but other researchers have told Nature some of the details. On 5 April, the Chinese scientists submitted their first major H7N9 paper, including analyses of the sequences, to The New England Journal of Medicine (NEJM).

Around the same time, the researchers learned that they might be scooped: several other research groups were preparing to publish papers on the virus, or already had done so, including analyses of the sequences in GISAID.

This news was followed by what seemed to be a snub. It emerged on 5 April that drug firm Novartis in Basel, Switzerland, and the J. Craig Venter Institute in Rockville, Maryland, planned to use the uploaded sequences to develop H7N9 vaccines. The initiative had US government funding and would be a collaboration with the US Centers for Disease Control and Prevention (CDC) in Atlanta, Georgia but not with the Chinese team. The Chinese researchers felt that this was not in the spirit of GISAID.

The sharing of flu-virus data and materials 
